\title{
Rancang Bangun Alat Proteksi Listrik Rumah Terhadap Kebocoran Gas LPG Berbasis Arduino
}

\author{
Muhammad Ziaul Khaq \\ Prodi Teknik Elektro, Fakultas Teknik, \\ Universitas Islam Lamongan $\mathrm{Jl}$. \\ Veteran No.53 A \\ Lamongan, Indonesia \\ muhammadziaulkhaq2206@gmail.com
}

\author{
Arief Budi Laksono \\ Prodi Teknik Elektro, Fakultas Teknik, \\ Universitas Islam Lamongan $\mathrm{Jl}$. \\ Veteran No.53 A \\ Lamongan, Indonesia \\ ariefbudila@gmail.com
}

\author{
Ulul Ilmi \\ Prodi Teknik Elektro, Fakultas Teknik, \\ Universitas Islam Lamongan $\mathrm{Jl}$. \\ Veteran No.53 A \\ Lamongan, Indonesia \\ ululilmi@yahoo.co.id
}

\begin{abstract}
Abstrak - Gas LPG sangat penting bagi kebutuhan manusia, Selain digunakan untuk keperluan dapur, LPG juga bisa digunakan sebagai bahan bakar kendaraan bermotor atau yang biasa disebut BBG(Bahan Bakar Gas). Bahkan menurut CNN Indonesia, pada tahun 2015 saja Pertamina melakukan impor 4,2 metrik ton LPG. Hal ini terkait dengan konsumsi masyarakat Indonesia terhadap penggunaan gas LPG. Namun dari banyak kelebihan yang bisa didapatkan dari pemanfaatan LPG, ada juga beberapa faktor berbahaya yang perlu diperhatikan. Seperti proses pemasangan tabung LPG yang kurang tepat, dan banyak faktor lain yang dapat menyebabkan terjadinya kebocoran gas yang nantinya dapat memicu kebakaran. Untuk itulah diperlukan alat yang dapat mendeteksi kebocoran gas dan memberikan proteksi listrik terhadap tempat yang terjadi kebocoran gas, serta notifikasi yang cepat supaya bisa dilakukan penanggulangan dini.
\end{abstract}

Berdasarkan masalah tersebut, penelitian ini melakukan berbagai pengujian untuk menciptakan rancang bangun agar dapat bermanfaat untuk mengantisipasi terjadinya ledakan yang diakibatkan oleh bocornya gas LPG. Metode yang digunakan meliputi perancangan elektrik dan sistematis. Tahapan yang dilakukan meliputi tahapan studi pustaka kemudian perancangan, pembuatan hardware dan software mengintegrasikan sistem dan pengujian serta analisa sistem. Mempertimbangkan teori-teori tersebut dan dapat mengetahui pemograman mikrokontroller arduino uno, sensor mq 2 , buzzer, LED, modul ESP 8266/ ESP-01, fan exhaust, relay, power supply, serta aplikasi smartphone Blink.

Pada penelitian ini menggunakan beberapa pengujian, diantaranya pengujian mikrokontroller arduino uno, sensor mq 2, buzzer, LED, modul ESP 8266/ ESP-01, fan exhaust, relay, power supply, serta aplikasi smartphone Blink. mikrokontroller arduino uno sebagai otak utama penyimpan program. fan exhaust penyetabil kandungan udara. sensor mq 2 sebagai pendeteksi gas. buzzer, LED, modul ESP 8266/ ESP01 dan aplikasi smartphone Blink sebagai output pemberi notifikasi serta pertanda terjadinya kebocoran gas, dan relay sebagai eksekutor pemutus aliran listrik dalam rumah jika terjadi kebocoran gas LPG dalam rumah dengan kadar kebocoran gas diatas $10 \mathrm{ppm}$ maka rancang bangun ini akan bekerja sesuai yang di jabarkan diatas.

Kata Kunci-Gas LPG, sensor mq 2, Arduino uno, Poteksi listrik dan Notifikasi

\section{Pendahuluan}

Gas LPG sangat penting bagi kebutuhan manusia, Selain digunakan untuk keperluan dapur, LPG juga bisa digunakan sebagai bahan bakar kendaraan bermotor atau yang biasa disebut BBG (Bahan Bakar Gas). Bahkan menurut CNN Indonesia, pada tahun 2015 saja Pertamina melakukan impor 4,2 metrik ton LPG. Hal ini ISSN 2615-5788 Print (2615-7764) C2020 JURNAL TEKNIK ELEKTRO DAN KOMPUTER TRIAC Vol. 7 No. 2 Tahun 2020 terkait dengan konsumsi masyarakat Indonesia terhadap penggunaan gas LPG. Namun dari banyak kelebihan yang bisa didapatkan dari pemanfaatan LPG, ada juga beberapa faktor berbahaya yang perlu diperhatikan. Seperti proses pemasangan tabung LPG yang kurang tepat, dan banyak faktor lain yang dapat menyebabkan terjadinya kebocoran gas yang nantinya dapat memicu kebakaran. Untuk itulah diperlukan alat yang dapat mendeteksi kebocoran gas dan memberikan proteksi listrik terhadap tempat yang terjadi kebocoran gas, serta notifikasi yang cepat supaya bisa dilakukan penanggulangan dini.

Berdasarkan permasalahan di atas, maka penulis ingin merancang suatu alat yang dapat memproteksi listrik serta pemberi notivikasi (tanda-tanda) yang sangat cepat jika terjadi kebocoran tabung gas LPG serta memberi notifikasi lewat aplikasi blnyk pop-up yang terinstal. Penelitian bertujuan merancang alat bangun proteksi listrik dengan dilengkapi sistem alarm dan pembuang gas dalam ruangan, serta dapat mengirim notifikasi ke handphone android berbasis IoT (internet of things) jika terjadi kebocoran gas LPG. Hal tersebut bertujuan agar mengantisipasi terjadinya kebakaran atau bahkan ledakan yang terjadi akibat suatu ruangan penuh dengan gas kemudian adanya suatu percikan listrik sehinga memicu terjadinya suatu hal yang tidak diinginkan. Oleh sebab itu peneliti ingin mengantisipasi terjadinya percikan listrik tersebut dengan cara memberi proteksi listrik pada sumber utama listrik rumah, yaitu di bagian MCB sekering rumah. Sehingga berimbas pada putusnya seluruh aliran listrik dalam rumah ketika terjadi kebocoran gas, kemudian disusul dengan adanya alarm dan kipas pembuang gas dalam ruangan ( dapur ) yang menyala dan mengirim notifikasi lewat aplikasi telegram ke penghuni rumah, ketika kadar gas sudah habis dalam ruangan tersebut, listrik rumah kembali teraliri arus listrik disusul dengan matinya kipas pembuang dan alarm yang menyala tadi.

\section{BAHASA DAN METODE}

Metode yang digunakan dalam penelitian adalah perancangan elektrik, sistematis, agar diperoleh data dan informasi yang akurat. Dalam perancangan ini dimulai dari pengumpulan data, pembuatan perancangan, pembuatan alat, pengujian, dan menyimpulkan hasil dari sistem. Berikut ini merupakan diagram blok dari sistem proteksi listrik rumah terhadap kebocoran gas LPG berbasis arduino, serta memberikan notifikasi ke pemiik 
rumah jika telah terjadi kebocoran gas LPG dengan sistem IoT melalui aplikasi Blink.

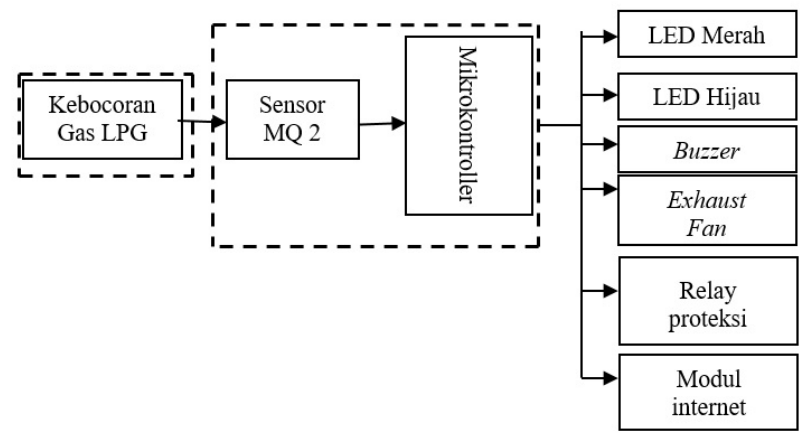

Gambar 1. Blok Diagram Perencanaan Ala

1. Tahap Studi Pustaka.

Studi pustaka ini diambil dari beberapa jurnal dan juga buku - buku referensi yang digunakan sebagai dasar untuk mengolah data yang ada.Studi pustaka pada tugas akhir ini meliputi hal - hal sebagai berikut:

a. Studi system operasi mikrokontroller arduino dan internet of things (IOT).

b. Studi karakteristik sensor MQ-2.

c. Studi gas LPG dan Studi sistem proteksi listrik rumah

2. Tahap perancangan dan pembuatan hardware

Perancangan alat proteksi listrik rumah terhadap kebocoran gas LPG berbasis arduino pendeteksi gas karbon monoksida sebagai pengaman di dalam ruangan disesuaikan dengan fungsi dari komponen komponen yang akan digunakan sehingga siap untuk direalisasikan.

3. Tahap perancangan dan pembuatan software

Pengujian perangkat penyusun system yang sudah dirancang, yaitu perangkat keras dan perangkat lunak sebelum diintegrasikan menjadi system keseluruhan.

4. Tahap integrasi sistem

Mengintegrasikan antara Hardware dan Software yang telah disusun menjadi sistem keseluruhan untuk menjalankan sistem tersebut berjalan dengan baik.

5. Tahap pengujian dan analisa sistem

Menguji sistem yang telah terintegrasi secara menyeluruh untuk selanjutnya dilakukan analisa sesuai dengan fungsinya.

Flowchart system kerja perancangan perangkat lunak seperti terlihat pada gambar.

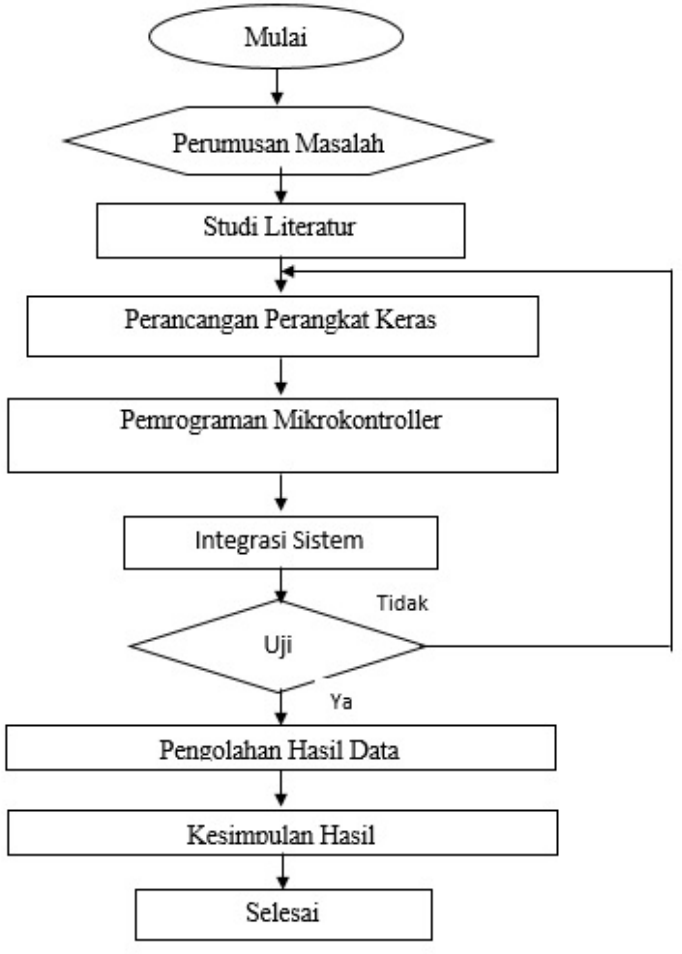

Gambar 2. Flowchart Pembacaan Sensor

\section{HASIL DAN PEMBAHASAN}

a. Hasil pengujian sensor MQ 2

Pengujian sensor MQ2 dilakukan untuk mendeteksi gas - gas berbahaya, terutama gas LPG. Pengujian sensor ini menggunakan gas LPG, gas butana, gas bensol. yang sebelumnya sensor MQ2 telah dimasukkan program melalui board arduino dan programnya telah disimpan kedalam IC mikrokontroller Arduino Uno. Untuk mendapatkan hasil yang baik dan maksimal.

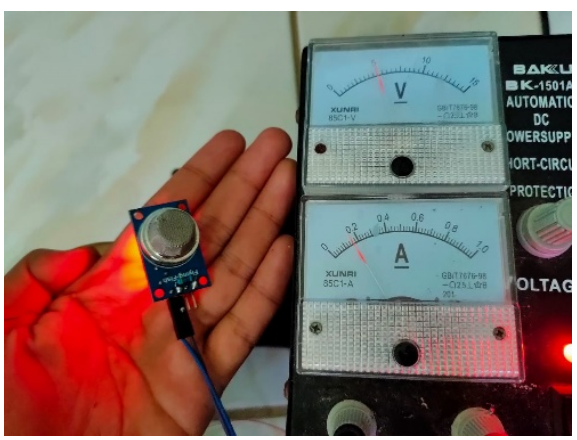

Gambar 3. Pengujian sensor MQ 2 
TABEL I. Pembacaan sensor MQ 2

\begin{tabular}{|l|c|c|c|}
\hline \multicolumn{1}{|c|}{ Percobaan } & Waktu & Jarak uji & $\begin{array}{c}\text { Nilai } \\
\text { Sensor }\end{array}$ \\
\hline Gas LPG & 5 detik & $5 \mathrm{~cm}$ & $15230 \mathrm{ppm}$ \\
\hline Korek bensol & 5 detik & $5 \mathrm{~cm}$ & $2022 \mathrm{ppm}$ \\
\hline Gas butana & 5 detik & $5 \mathrm{~cm}$ & $9015 \mathrm{ppm}$ \\
\hline Gas LPG & 10 detik & $5 \mathrm{~cm}$ & $50501 \mathrm{ppm}$ \\
\hline Korek bensol & 10 detik & $5 \mathrm{~cm}$ & $7319 \mathrm{ppm}$ \\
\hline Gas butana & 10 detik & $5 \mathrm{~cm}$ & $31744 \mathrm{ppm}$ \\
\hline Gas LPG & 15 detik & $5 \mathrm{~cm}$ & $55023 \mathrm{ppm}$ \\
\hline Korek bensol & 15 detik & $5 \mathrm{~cm}$ & $7680 \mathrm{ppm}$ \\
\hline Gas butana & 15 detik & $5 \mathrm{~cm}$ & $30726 \mathrm{ppm}$ \\
\hline
\end{tabular}

b. Hasil pengujian arduino uno

Untuk mendapat hasil yang baik dalam pengujian, maka proses pengujian mikrokontroller dapat dihubungkankan dengan tegangan yang memiliki nilai 9 volt. Apabila mikrokontroller menyala, maka mikrokontroller dalam kondisi baik dan bisa digunakan.

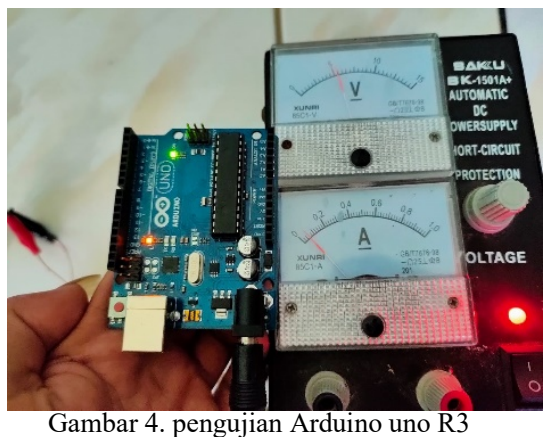

c. Hasil Pengujian LED dan Buzzer untuk Notifikasi pengujian LED dan Buzzer dihubungkan pada pin - pin mikrokontroller atau diberi tegangan sebesar 5 volt. Apabila LED dan Buzzer menyala, maka LED dan Buzzer berfungsi dengan baik dan siap untuk digunakan.

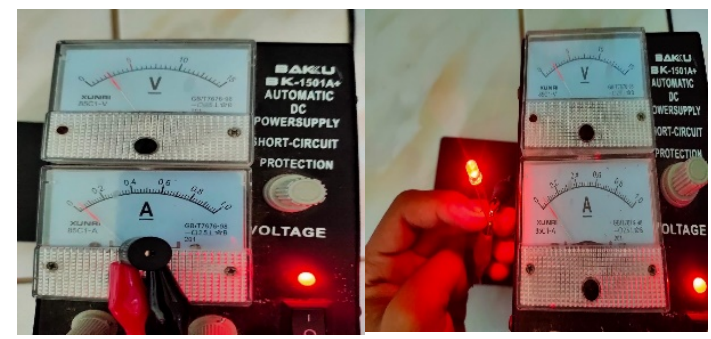

Gambar 5. pengujian LED dan Buzzer

d. Hasil Pengujian exhaust fan

Untuk mendapatkan hasil yang baik dalam pengujian, maka proses pengujian dilakukan dengan menghubungkan pada pin-pin $\mathrm{NO} / \mathrm{NC}$ dan $\mathrm{COM}$ relay yang sudah terkoneksi dengan arduino.
TABEL II. Pengujian Exhaust Fan

\begin{tabular}{|c|c|c|}
\hline PIN COM & PIN NC & STATUS \\
\hline 0 Volt & 0 Volt & Off \\
\hline 220 Volt & 220 Volt & On \\
\hline
\end{tabular}

Dari tabel pengujian diatas, menunjukkan bahwa apabila exhaust fan diberi tegangan sebesar 220 volt, maka status exhaust fan akan on/menyala. Sedangkan apabila exhaust fan tidak diberi tegangan, maka status exhaust fan akan off / mati. Hal itu menandakan bahwa exhaust fan berfungsi dengan baik.

e. Hasil pengujian relay proteksi

Untuk mendapatkan hasil yang baik, pengujian relay diberi sumber tegangan sebesar 5 volt sebagai pemicu dari coil relay.

\begin{tabular}{|c|c|c|}
\hline Input (VDC) & $\begin{array}{c}\text { NO (Normally } \\
\text { Open) }\end{array}$ & $\begin{array}{c}\text { NC (Normally } \\
\text { Close) }\end{array}$ \\
\hline $0.00 \mathrm{v}$ & On & Off \\
\hline $5,00 \mathrm{v}$ & Off & On \\
\hline
\end{tabular}

TABEL III. Hasil Pengujian Relay

Dari hasil pengujian diatas, ketika relay belum mendapat tegangan dari mikrokontroller keadaan relay dalam kondisi normally open (NO) dan ketika mendapat tegangan $5 \mathrm{v}$ keadaan relay berubah menjadi normally close (NO).

f. Hasil pengujian modul esp 8266-01

Pengujian Modul 8266 / ESP-01 dilakukan dengan menghubungkan pin TX, RX, vcc, dan gnd dari modul esp ke Ardino, dilanjut dengan memasukakan program ke arduino agar arduino dapat mengakses modul wifi ini. Jika sudah selesai maka dilakukan pengetesan alat secara keseluran, jika berhasil maka akan mendapat notifikasi pada handphone android melalui aplikasi Blynk.

Jika berhasil terkoneksi maka led indikator yang berada pada modul akan berkedip secara berlahan berbeda ketika proses scaning jaringan dan proses pengkoneksian yang berkedip dengan cepat. Proses perancangan dapat dilihat pada gambar.

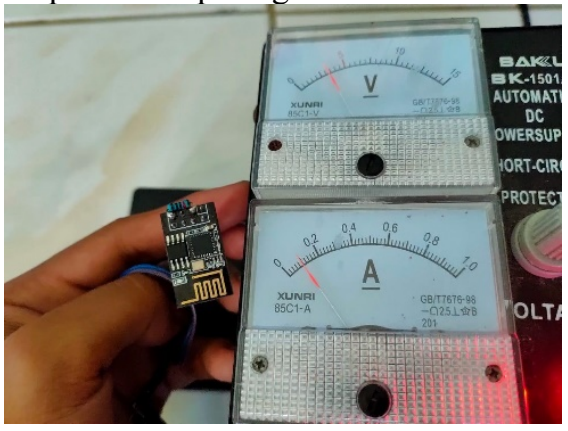


detektor gas LPG yang mengacu pada nilai ambang batas $10 \mathrm{ppm}$.

g. Pengujian keseluruhan

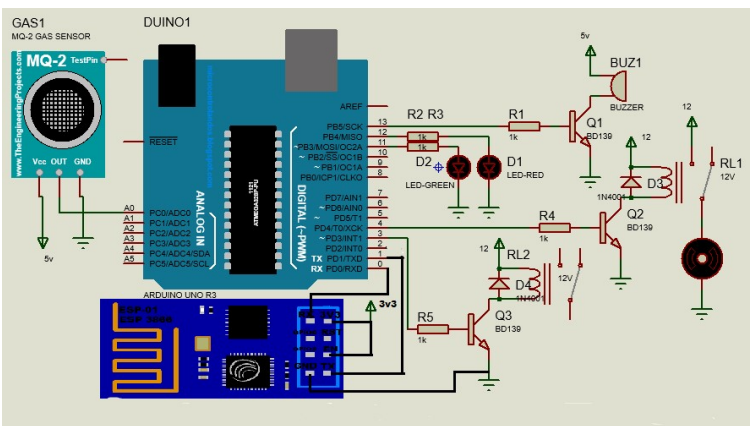

Gambar 7. Skema pengujian keseluruhan

Tahap ini bertujuan untuk mengetahui kinerja rangkaian keseluruhan yang meliputi pengujian relay proteksi, sensor MQ2, pengujian buzzer, pengujian exhaust fan, modul IOTdan pengujian LED. Proses pengujian dilakukan dengan memasukkan gas LPG ke dalam suatu ruangan. Apabila kadar gas LPG yang terdeteksi melebihi ambang batas, maka sistem akan berkerja dengan memproteksi listrik rumah, mengirim notifikasi berbasis IOT, menyalakan LED merah, buzzer dan exhaust fan akan menyala. Hasil pengujian dapat dilihat dalam tabel sebagai berikut.

\begin{tabular}{|l|c|c|c|c|c|c|}
\hline \multicolumn{1}{|c|}{ Percobaan } & $\begin{array}{c}\text { Gas CO } \\
\text { (ppm) }\end{array}$ & LED & Buzzer & $\begin{array}{c}\text { Exhaust } \\
\text { Fan }\end{array}$ & proteeksi & $\begin{array}{c}\text { Notif } \\
\text { IOT }\end{array}$ \\
\hline Udara bersih & $0.00 \mathrm{ppm}$ & Hijau & Off & Off & Off & Off \\
\hline $\begin{array}{l}\text { Udara } \\
\text { tercemar gas }\end{array}$ & $>10 \mathrm{ppm}$ & Merah & On & On & On & On \\
\hline
\end{tabular}

Dari tabel pengujian rangkaian alat secara keseluruhan, apabila nilai kadar gas LPG dalam kondisi normal, maka LED akan menyala berwarna hijau dan respon dari relay proteksi, notifikasi IoT, buzzer serta exhaust fan akan mati. Apabila nilai kadar gas LPG mencapai 10 ppm, maka listrik rumah akan terproteksi, modul IOT mengirim notifikasi, LED akan menyala berwarna merah, buzzer akan menyala dan exhaust fan akan menyala.

\section{KESIMPULAN}

Berdasarkan hasil analisis dan pembahasan yang didapat pada penelitian ini dapat disimpulkan :

1. Telah membuat proteksi listrik terhadap kebocoran gas LPG untuk antisipasi pengaman terhadap ledakan rumah yang diakibatkan oleh bocornya gas LPG berbasis arduino dengan dilengkapi fitur IoT yang memungkinkan pengontrolan dari jarak jauh. Dengan menggunakan sensor MQ2 sebagai
2. Agar arduino dapat melakukan perintah proteksi listrik rumah, menyalakan buzzer peringatan dan menyalakan kipas pembuang serta mengirim notivikasi ke handphone dengan sistem IoT (internet of things) saat terjadi kebocoran gas LPG, maka arduino harus dilakukan pemerograman dengan pembacaan input berupa sensor MQ 2, dan output berupa buzzer, LED, modul ESP 8266/ ESP01, fan exhaust dan relay.

3. Agar arduino dapat mengirim notifikasi ke handphone android menggunakan sistem IOT (internet of things) dengan sistem aplikasi Blynk jika terjadi kebocoran gas, maka arduino harus menerima input dari sensor MQ 2 dengan minimal pembacaan sebesar 10ppm. Jika pembacaan sensor MQ 2 lebih dari 10ppm maka arduino akan memerintahkan relay memutus jaringan listrik rumah, modul ESP 8266/ ESP-01 mengirim notifikasi ke smartphone penguna yang telah terinstal aplikasi blink, menyalakan LED merah dan buzzer serta menyalakan exhaust fan untuk menetralisir kadar gas dalam ruangan. Jika kadar gas dibawa 10 ppm maka semua output dari arduino uno tersebut akan off terkecuali led hijau yang menyala sebagai indikator.

\section{DAFTAR PUSTAKA}

[1] Agustinus, Leonard, Fatma Agus Setyaningsih dan Tedy Rismawan. 2015. "Rancang BangunPrototype Pendeteksi Kadar CO Sebagai Informasi Kualitas Udara Berbasis Mikrokontroller". Fakultas MIPA, UniversitasTanjungpura. Pontianak.

[2] Asbi, Zulfahmi. 2010. "Pengontrolan Ketinggian Permukaan Air Berbasis Mikrokontroller 8535" Skripsi, Program Studi Teknik Elektro Fakultas Sains dan Teknologi Universitas Islam Negeri Sultan Syarif Kasim Riau, Pekanbaru

[3] Aziz, M. Nur. 2016. "Rancang Bangun Sistem Monitoring Kadar Gas Karbon Monoksida dan Senyawa Hidrokarbon pada Kabin Mobil Menggunakan Sensor Gas TGS 2201 Berbasis Arduino" Skripsi, Fakultas Sains dan Teknologi, Universitas Islam Negeri Maulana Malik Ibrahim Malang.

[4] Aminah, Nur. 2016. "Rancang Bangun Rangkaian Elektronik Sebagai Alat Proteksi Otomatis Pada Instalasi Listrik Rumah Tinggal". Teknik Elektronika PNUP.

[5] Fardiaz. 1992. "Polusi Air danUdara". Penerbit Kanisius, Yogyakarta.

[6] Haryanti, Munnik, Muhammad Saleh. 2017. "Rancang Bangun Sistem Keamanan Rumah Menggunakan Relay" Program Studi Teknik Elektro Universitas Suryadarma, Jakarta

[7] Hakim, Ismail. 2017. "Alat Ukur Konsentrasi Karbon Monoksida (CO) Pada Ruangan BerbasisATMega 8535 dengan Sensor MQ7 dan Indikator Buzzer". Tugas Akhir, Fakultas Matematikada Ilmu Pengetahuan Alam, Universitas Sumatera Utara. Medan.

[8] Koesegeren, Viktor V. 2013. "Perancangan AlatUkur Kadar Karbon Monoksida (CO), Karbon Dioksida $\left(\mathrm{CO}_{2}\right)$ dan HidroKarbon (HC) Pada Gas Buang Kendaraan Bermotor". FakultasTeknik UNSRAT. Manado.

[9] Kurniawan,Moh. Andre. 2019. "Rancang Bangun Alat Pendeteksi Karbon Monoksida Sebagai Pengaman Dalaam Mobil Berbasis Mikrokontroller". Skripsi Fakultas Teknik, JurusanTeknikElektro, Unifersitas islam Lamongan.

[10] Liangdo, Yohanesdan Antonius Wibowo. 2008. "Sistem Monitoring danPengontrol Kadar Gas KarbonMonoksida (CO) DalamRuangan". FakultasTeknik, JurusanTeknikElektro, UniversitasKatolikWidya Mandala. Surabaya.

[11] Listiono,Mery Hadi. 2019. "Rancang bangun Aalat Pendeteksi Karbon Monoksida Untuk pengaman Sirkulasi Udara Diruangan 
[12] Berbasis Mikrokontroller". Skripsi FakultasTeknik, JurusanTeknikElektro, Unifersitas islam Lamongan.

[13] Lowongan, Tander Risard, Pratolo Rahardjo dan Yoga Divayana. 2015. "Detektor LPG Menggunakan Sensor MQ2 Berbasis Mikrikontroller ATMega328” Mahasiswa Jurusan Teknik Elektro, Fakultas Teknik Universitas Udayana.

[14] Meliyanto, Nindi dan Bambang Eka, 2014. "Pengendali Kipas Sirkulasi Udara Melalui Deteksi Suhu Udara dan Kadar Karbon Dioksida Berlebih" Universitas Surakarta

[15] Nebath, Evert, David Pang, ST., MT danJanny O. Wuwung, ST., MT. 2014. "Rancang Bangun Alat Pengukur Gas Berbahaya CO dan $\mathrm{CO}_{2}$ di Lingkungan Industri". Fakultas Teknik Jurusan Teknik Elektro UNSRAT. Manado.

[16] Pratama Dimas. "Sistem Kontrol Level Air Tandon PDAM Berbasis AndroidVia Wifi Menggunakan Sensor Ultrasonik Di PDAM Lamongan". Skripsi FakultasTeknik, JurusanTeknikElektro, Unifersitas islam Lamongan.

[17] R.F. Talumewo, 2012. "Rancang Bangun Alat Pengkondisi Udara Pada Ruangan Menggunakan Sensor Co Dan Temperatur", TugasAkhir, FATEK UNSRAT, Manado

[18] Rafiuddin Syam, PhD. 2013 "Dasar - Dasar Teknik Sensor". Makassar. Ebook

[19] Rahman, M.S. 2007. "Buck Converter Design Issues". Swedia: Linkoping Institute of Technology.

[20] Santoso, Hari. 2015, Panduan Praktis Arduino Untuk Pemula. Trenggalek. E-book

[21] Setiani, Astrid. 2015. "RancangBangunPower Supply untuk Mesin Electrical Discharge Machining". Skripsi, Fakultas Matematika dan Ilmu Pengetahuan Alam, Universitas Negeri Semarang.

[22] Triana, Anggi Novi. 2018. "Prototype Alat Penurun Nilai Konsentrasi Gas Karbon MonoksidaPada Ruang Merokok Berbasis Auino Nano Dengan Metode Lucutan Korona". Proyek Akhir, FakultasTeknik Universitas Negeri Yogyakarta 